\title{
RATIONAL EGOISM, ANIMAL RIGHTS, AND THE ACADEMIC CONNECTION
}

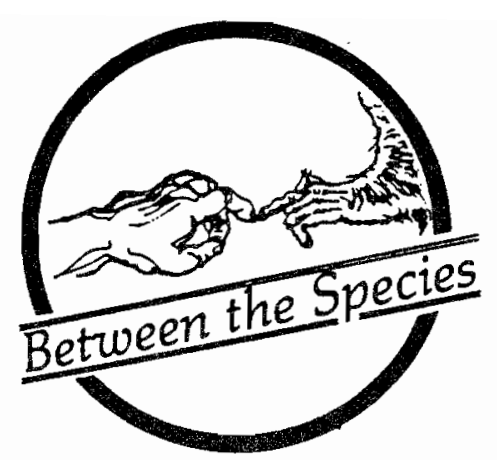

\author{
GEORGE CAVE \\ Trans-Species Unlimited
}

In his article "Animal Rights,"[1] Jan Narveson presents an alternative "moral" theory to what he calls the "Singer-Regan position." This theory--"rational egoism"-would exclude non-human animals from moral consideration and deny them all rights. His excuse for developing this "nasty doctrine" is that he is "not convinced that they [Singer and Regan] are right" and that "there is much to be learned from doing so." Regan replies to this argument in his article "Narveson on Egoism and the Rights of Animals,"[2] and now Dale Jamieson has entered the debate with his "Rational Egoism and Animal Rights,"[3] a critique both of Narveson's position and of Regan's rebuttal.

Neither of these rejoinders to Narveson's argument is very effective. Both ignore its principal weakness and are thoroughly speciesist, leaving open the possibility of justifying the continued abuse of animals. In the present paper, [4] I try to explicate the principal flaw in Narveson's position (section one), show the inadequacy of Regan's and Jamieson's replies (section two), and suggest the basis for a more cogent critique of "rational egoism" (section three). In the final section of the paper, I argue that analysis of these articles reveals the danger of enervation faced by any liberation movement when its issues become the focus of debate within an acadenic context.

\section{$i$}

Narveson's argument. is briefly as follows: the foundation of morality is not, as Singer and Regan would have it, the recognition that all animals have the right to equal treatment in cases in which they would. suffer evil as a result of being denied it. on the contrary, rights are based solely upon mutual agreement between "rational" agents with a view toward reciprocal maximization of egoistic self-interest. Since non-human animals can neither assert self-interested claims as "rights" nor force from human beings the recognition of them by virtue of the power to infringe on corresponding human "rights," non-human animals have no rights. We human beings are, therefore, "morally" entitled to abuse animals in any way we see fit so long as such treatment does not infringe on our own self-interest (as it might, for example, if we beat an expensive riding horse to death).

Narveson proceeds to consider the case of morons and children as the basis of a possible objection to his theory. Children who are very young would seem to lack the capacity to assert self-interested claims, and almost all of them certainly lack the coercive power to get these claims recognized as "rights." similarly, depending on their degree of debilitation, morons cannot assert claims, and though many may have the coercive power to infringe on others' "rights," they are not likely to realize that the guarantee of the recognition of their own claims as "rights" depends on not infringing on others" corresponding "rights." A "rational" egoist will, thus, have no "rational" basis for respecting the "rights" of morons, since the morons will probably not respect him/her. Narveson's implicit conclusion, therefore, is that children and morons, like non-human animals, have no rights. But is this a telling objection to the theory of rational egoism? Only if children's and moron's lack of rights in some way results in the diminishment of other rational egoists' self-interests.

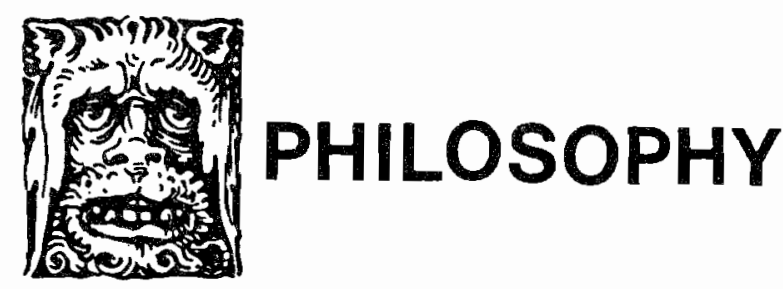


Peculiarly enough, however, the objection to rational egoism as formulated above does not appear to be the objection which Narveson tries to counter in his article. He is not trying to prove that the denial of rights to children and morons does not reduce other rational egoists' self-interests. Rather, he seems to be trying to prove that such a denial of rights need not involve treatment of children and morons which is different from that accorded to other human beings who possess rights, and precisely for the reason that it is not in the self-interest of rational egoists to treat them differently. That this is the true meaning of Narveson's response is evident from the fact that he refers to this objection as "Singer's and Regan's argument from marginal cases." Singer's and Regan's point is not that denying children and morons rights will result in a diminution of rational egoists' self-interests, and is, therefore, inconsistent with their position, but that the denial of rights will lead to abuse of children and morons, which is morally wrong. But a rational egoist who is consistent has no reason to share this concern. Mistreatment of children and morons can be of no moral concern to a rational egoist, unless it results in the reduction of his/her own self-interests. Such an objection, in fact, is completely irrelevant, for it is based on a moral premisethat it is wrong deliberately to inflict evil-which the rational egoist explicitly rejects.

It would seem, however, that Narveson is inconsistent in his reasoning. He seems to share Singer's and Regan's concern, as is indicated both by the fact that he attempts to refute the "arguments from marginal cases" and by his rejection of cannibalism. He seems, at one and the same time, to want to deny that there is any moral ground for rights except egoistic seif-interest, and yet to protect human beings who possess no rights from the abuse which might result from such a denial. The only way in which he can do this, without exposing himself to the charge that he provides no justification for preferential treatment of human beings without rights as compared to non-human animals, is to try to show that although children and morons, like non-human animals, have no rights, it is, nonetheless, in the selfinterest of rational egoists to treat then equally. Narveson would say, of course, that it is not in their self-interest to treat non-human animals equally.
According to Narveson, a rational egoist will treat children as though they had rights, because the self-interests of rationally egoistic parents include the self-interests of their children (moronic or otherwise). Since they want their own children protected, they will respect other people's children as well. Moreover, according to Narveson, a rational egoist has "nothing to gain from being permitted to invade the children of others" (a highly questionable assumption, as witness child migrant laborers). But what about orphans? Since these children have no parents, their abuse would not seen to diminish other rational egoists' self-

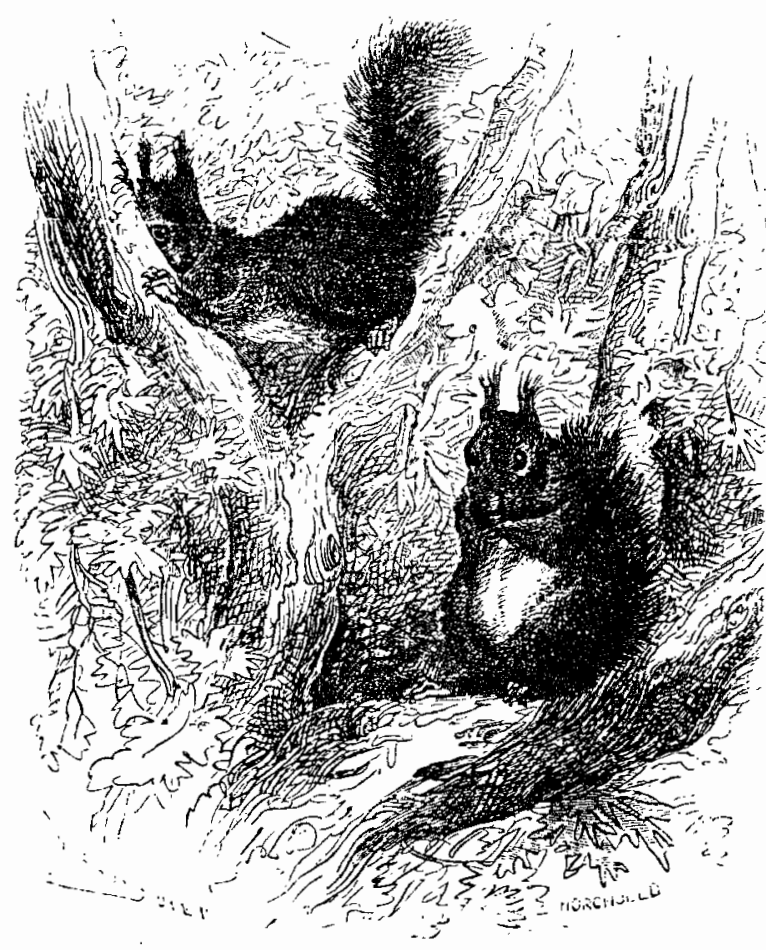

interests. Narveson has an answer which is applicable to this case, but it is very weak:

we have an interest in the children of others being properly cared for because we don't want them growing up to be criminals or delinquents, etc.

Presumably, this would apply not only to children with parents but to orphans as well. It is, however, based on a highly speculative possibility which is unlikely to be decisive in determining a rational egoist's calculations of self-interest at any given time. Moreover, it is obvious that not all forms of abuse lead to criminal tendencies.

Narveson thinks a rational egoist will treat (adult) morons equally lest he not be 
treated equally were he to become a moron. To this "rational" argument, Narveson appends two "non-rational" bases for equal treatment of (adult) morons, which would presumably also apply to children (morons or otherwise). The first is that a moron's rational relatives may have a "sentimental interest" in his being treated equally. It is unclear in what sense, if any, this "sentimental interest" is a form of self-interest. Moreover, as Regan points out in his reply, it seems obvious that such sentimental interest does not always exist. The other factor is "sentiment-generalization," the human tendency to extend sympathy to members of one's own race, species, etc. it seems quite clear that this is not consistent with egoistic self-interest.

\section{ii}

Both Regan and Jamieson reply to Narveson's argument by trying to show that it is not necessarily true that the self-interest of rational egoists will always guarantee that children and morons, though lacking rights, will be treated equally. Regan limits himself to the case of idiots, arguing that is unnecessary, from the perspective of rational egoism, to accord equal treatment to all idiots in order to guarantee protection for oneself in the event that one became an idiot. All that would be necessary is to guarantee continued equal treatment of all those who became idiots. This leaves the door open to abuse of congenital (adult) idiots, since such abuse would in no way violate the rational egoists' self-interest. Nor will "sentimental interest," as already pointed out, guarantee equal treatment of congenital idiots, since many of them are not the objects of such interest.

Jamieson criticizes this second argument on the grounds that a rational egoist could respond that the "epistemological problems" involved in determining who is the object of sentimental interest are so severe that all idiots should be included in the "ambit of morality." Quite apart from the question as to whether "sentimental interest" is a form of self-interest, this seems to me an extremely quibbling, if not patently false, objection to Regan's argument.

Nor are Jamieson's own arguments any stronger. He asserts that the concept of egoistic self-interest is fluid, and that we, consequently, might came to the view that idiots are "obscene moral failures" who should be exterminated. Jamieson's position is that such an alteration in a rational egoist's concept of his/her own self-interest would result in his/her former self-interest in favor of idiots being treated fairly being outweighed, and that the abuse of idiots would then be mandated by self-interest. It is extremely unclear, however, in what sense the extermination of idiots would serve one's self-interests. In what way would the mere existence of idiots who are seen as "obscene moral failures" involve a reduction in a rational egoist's self-interests?

Jamieson also hypothesizes that a population explosion could result in a view of human fetuses as a threat to survival and as. therefore, contrary to one's self-interests. Were this to happen, we might resort to cannibalism for the sake of our self-interest. Anything, of course, is possible, but these "fables," as Janieson rightly calls them, bear more resemblance to the idle and rather paranoid speculations which underlie the domino theory in politics than to a cogent retort to rational egoism.

If it could be conclusively proven that it is not in the self-interest of rational egoists to treat children and morons as

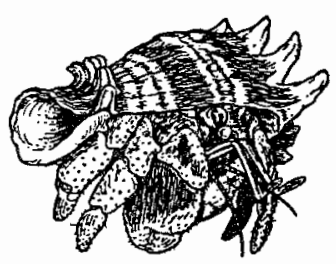

though they had rights, this would, of course, force Narveson to account for how we can justify equal treatment in their case and not in the case of non-human animals. Such a justification, I believe, could not be provided. Narveson would then be forced (assuming that he would not simply adhere dogmatically to an inconsistent position) either to become a pure rational egoist who would deny equal treatment to children and idiots or. to extend equal treatment to non-human animals as well. But in the latter case, the doctrine of rational egoism will have conpletely collapsed as an effective guide to "moral" conduct. In so far as Regan's and Jamieson"s articles push Narveson toward this philosophical dilema, they are valuable and worthy of philosophical attention.

As a defense of animals, however, both articles suffer from very severe defects. In (cont. p. 25) 
the first place, they are effective only to the extent that Narveson is inconsistent in his reasoning, i.e., is not a pure rational egoist. To a pure rational egoist, both Regan's and Jamieson's criticisms are completely irrelevant.

Even granted that Narveson is inconsistent, Regan's and Jamieson"s arguments are seriously deficient in other respects. Not only do they both ignore many of the weaknesses in Narveson's argument for equal treatment of children and idiots which I have pointed out above, but their own arguments (particularly Jamieson's) do not convincingly establish that it is not in a rational egoist's self-interest to treat children and idiots equally.

More importantly, the very nature of their approach to the problem leaves open the possibility of justifying the continued abuse of non-human animals. By accepting the issue on Narveson's own terms, Regan and Jamieson grant him the opportunity of trying to produce more convincing arguments from selfinterest for the equal treatment of children and idiots. Were he successful in doing this, then the continued abuse of non-human animals, which does not compromise our selfinterest, would be justified. For in this case, there would be no contradiction of the principle of rational egoism in treating children and idiots--but not non-human animals-as though they had rights. Whether this can be done is highly questionable. The point, however, is that in leaving open this possibility, Regan's and Jamieson's arguments are defective in principle.

Finally, these arguments are objectionable because they are incorrigibly speciesist. This is due, once again, to the fact that both Regan and Jamieson accept the problem on Narveson's own terms. Both philosophers argue, in effect, that it is wrong to abuse animals because it leads to unjustified abuse of human beings. [5]

\section{iii}

What form, then, would effective rebuttal to Narveson' s position take? Narveson's attempt to refute the "argument from marginal cases" reveals that he shares Singer's and Regan's concern lest children and idiots be abused, a concern which is rooted in moral assumptions which he supposedly rejects and which are inconsistent with a pure rational egoism. In order to avoid the charge of a further inconsistency, i.e., the granting of equal treatment to "rightless" humans but not to "rightless" non-human animals, he defends such treatment on the grounds of rational self-interest. Yet, his motivation, as I have tried to make clear, is not to avoid compromising human self-interest by treating children and idiots differently, but to ensure their equal treatment without at the same time compromising the principle of rational egoism. Narveson is inconsistent in attempting to prevent the abuse of children and idiots for non-rationally egoistic reasons, but consistent in utilizing rationally egoistic arguments to prevent such abuse.

His concern for children and idiots, however, amounts to an acknowledgement of the validity of the principle of equality with regard to the treatment of human beings. Consequently, he is open to the charge of unjustified preferential treatment of human beings in spite of the fact that he uses arguments from self-interest to support it. Egoistic self-interest is not the true ground for preferential treatment of "rightless" humans. This is the major weakness in Narveson's argument, which both Regan and Jamieson ignore. Narveson is obliged either to become a pure rational egoist, for whom equal treatment of children and idiots is a concern only insofar as it furthers his self-interests, or to explain why the principle of equality, which is applied to "rightless" humans, is not also applied to non-human animals.

iv

A profounder lesson, however, emerges from the consideration of these essays, namely, a recognition of the dangers to which liberation movements are subject when their ideological foundations beoome the topic of intellectual and scholarly debate within the acadenic community. Arimal rights advocates may rightly applaud the increasing interest of the academic world in the philosophical issues raised by animal rights, but they should never forget that in terms of the goal which they espouse--the alleviation of animal suffering-such interest is justified only to the extent that it contributes to enlightened attitudes toward non-human animals and effective political action on their behalf. This is not to say, of course, that they should simply ignore or reject philosophical arguments which run counter to the interests of non-human animals, nor that they should un- 
critically accept arguments which support animal rights. But it is essential that they learn to recognize their enemies. There is something morally abominable about the "objective" debates on moral issues which often take place in a university context, when a propelling sense of moral outrage is altogether lacking. A controlled sense of moral outrage is the absolutely indispensable prerequisite for keeping one's true moral goals in view; it is not equivalent to naive or dogmatic emotional fervor or fanaticism.

Where this moral outrage is lacking, there is a serious danger of gratuitous, destructive scepticism which is often justified on the grounds of intellectual curiosity, but which amounts to nothing more than moral capriciousness and intellectual cleverness. To such scepticism the same objection can be made as is rightly made to animal experimenters who justify the torture of animals on the grounds that it extends the sphere of human knowledge, even where such knowledge has no relevance whatsoever to the alleviation of suffering. This objection is that compassion must always preempt curiosity. The extension of human knowledge, where no reduction of suffering results, may be a good (although I am inclined to think it ranks very low on the scale of goods), but knowledge gained at the expense of the infliction of suffering is, to my mind, quite clearly an evil.

None of this is to be construed as a denial of the urgent necessity of providing a firm, theoretical foundation for the animal rights movement. The attempt to do so necessarily involves an unbiased and rigorous critical assessment not only of opposing arguments, but also of those which favor animal rights. Nor should we dogmatically assume that opposing arguments or critiques of pro-animal rights arguments are motivated by speciesism. A philosopher who is impelled by moral concern for non-human animals may render a valuable service by exposing weaknesses in arguments which are uncritically accepted. In a world, however, in which millions of non-human animals die annually in factory farms and experimental laboratories in the U.S. alone, it is morally repugnant to see philosophers engaging in gratuitous debates on highly technical and pragmatically irrelevant aspects of the moral issue of animal rights, or sowing the seeds of doubt concerning the justifiability of human treatment of non-human animals for no other reason than idle curiosity. Such scholarly efforts serve only to drain liberation movements of their life-blood, and if not actually inmoral, are at least utterly devoid of all redeeming moral conviction.

There may, however, be another motivation for such efforts. A fundamental error which often lies at the root of such efforts is the belief that all legitimate moral convictions are susceptible of absolute rational justification and that without such justification they are worthless. I am convinced, on the contrary, that there are fundamental moral intuitions which cannot be intellectually validated in a definitive way. When we becorne obsessed with intellectual "proofs" of moral positions, we are in danger of becoming deaf to the unequivocal outcry of moral outrage and the testimony of our unambiguous moral intuitions.

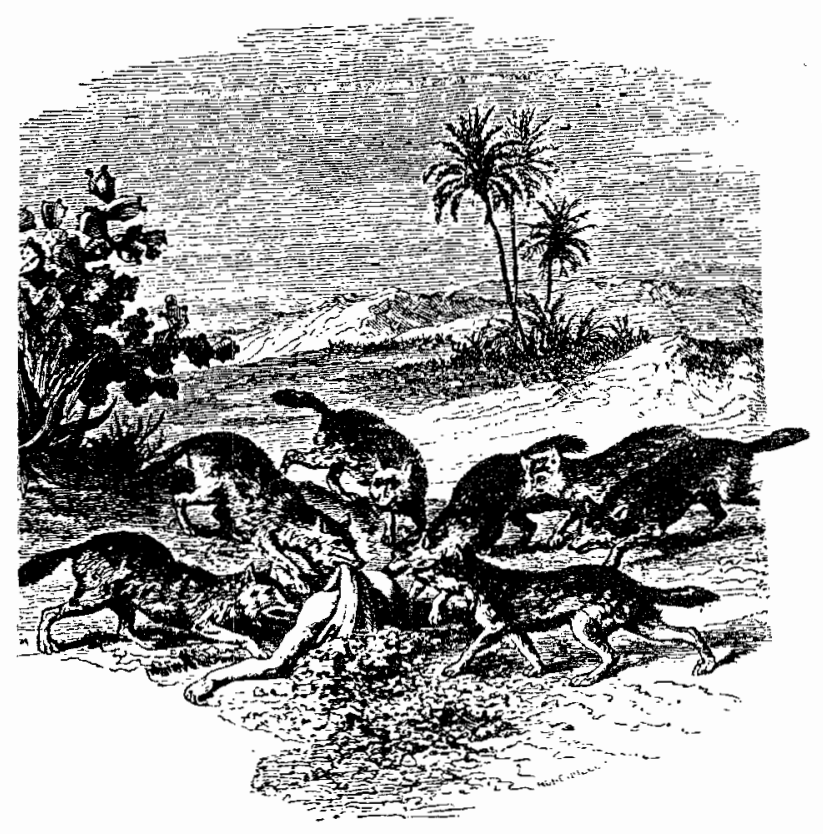

Such intuitions and outrage, of course, must always be brought before the court of reason, and where reason judges same incoherent $r c$ clearly false, they should be rejected. But the incapacity of reason to prove a position does not prove it wrong.[6]

The dangers outlined above are lurking in the articles discussed here, particularly in those of Narveson and Jamieson. Let us recall Narveson's justification for developing his theory of "rational egoism." He does so, he says, not "because I am convinced that Singer et. al. are wrong. I hope it is because $I$ am not convinced that they are right." This looks suspiciously like a combination of the intellectual curiosity and 
unbridled faith in reason criticized above. For it is clear from his article that Narveson has a great deal of sympathy for nonhuman animals. His summary of the "ReganSinger position" reads more like a sympathetic endorsement of that position--at least with regard to the factual abuses perpetrated on non-human animals--than a neutral, objective description of it. This is supported by other comments scattered throughout the article, e.g., the rejection of the argument that factory farm animals are better off for hav ing been granted the chance to exist, the reference to rational egoism as a "nasty doctrine," and so forth.

Assuming such a concern on Narveson's part, one might well ask why, if he is simply troubled by the ultimate cogency of Singer's and Regan's position, he does not address himself to exposing the weaknesses he finds in it. Rather than this, he develops the "nasty doctrine" of rational egoism, a doctrine which, as we have seen, he cannot bring himself to endorse whole-heartedly. How could the development of a theory which totally excludes non-human animals from moral consideration possibly be construed as an effective means of resolving his lingering doubts concerning the plausibility of Singer's and Regan's position? It would seem, on the contrary, to be a gratuitous exercise in destructive scepticism, which in no way serves the interest which (I hope) Narveson shares with Singer and Regan. I would suggest that the motivation for such an undertaking may well have been the intellectual curiosity and unbridled faith in reason discussed above.

Jamieson (and to a much less degree, Regan) succumb in their articles to the same morally counter-productive temptations. This is evident from the fact that they accept Narveson's formulation of the problem as the starting point of their criticism. As a consequence, they argue their cases in a thoroughly speciesist way and completely ignore the principal flaw in Narveson's argument, the exposure of wich would be the primary means of protecting the rights of animals. Thus, when Jamieson concludes his essay by saying that "because it is a bad moral theory, rational egoism fails to provide a solid basis for a principled indifference to the sufferings of animals," he is certainly correct, but not at all in the way that he imagines. Rational egoism is a "bad moral theory," not because the equal treat- ment of children and idiots cannot be guaranteed by considerations of egoistic selfinterest, but because the exclusion of nonhuman animals from ethical consideration is a moral outrage, which is totally unjustified if one accepts what I take to be a selfevident moral principle, namely, that the deliberate infliction of evil is always morally wrong.

\section{Notes}

1. Canadian Journal of Philosophy 7 (1977), pp. 161-78.

\section{Ibid., pp. 179-86.}

3. Environmental Ethics, 3 (1981), pp. $167-71$.

4. A small portion of the present paper appeared in slightly different form as a review of Dale Jamieson's article in Ethics $\underline{\varepsilon}$ Animals 2 (1981).

5. I am well aware, of course, that this is not representative of Regan's true position, nor, I suspect, of Jamieson's, but their arguments in these articles are thoroughly speciesist, nonetheless.

6. I would argue that the opposite is also true: the incapacity of reason to disprove a position does not prove it right.

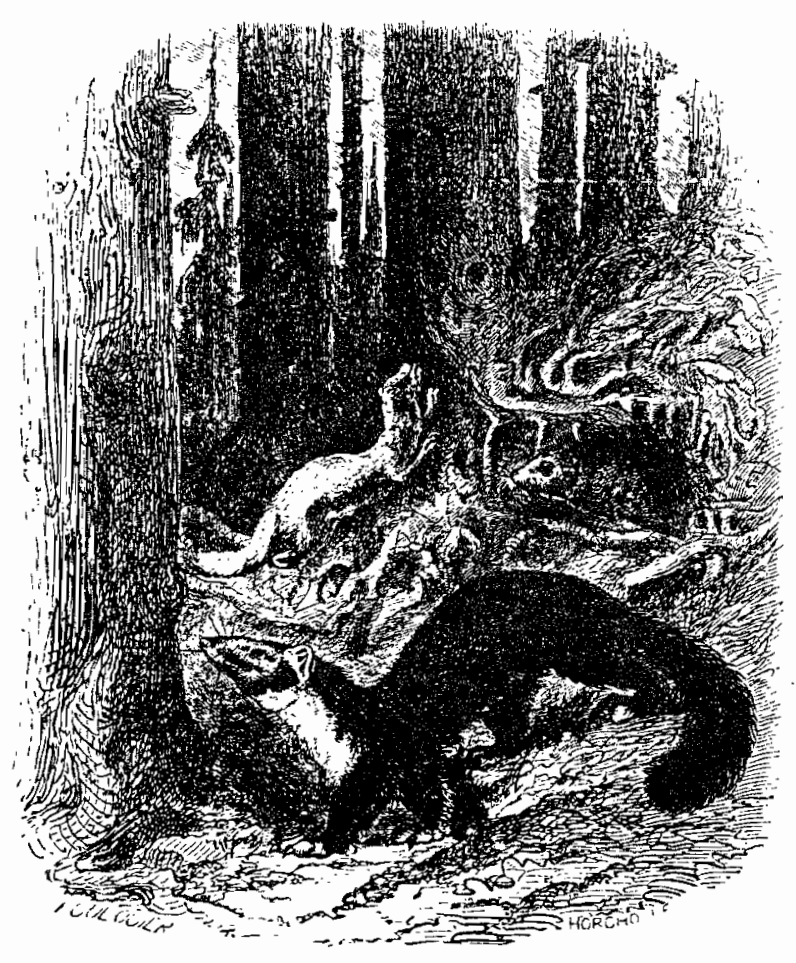

